\title{
A MOBILE APP TO EXPLORE CULTURAL AND HISTORICAL ASSOCIATIONS BETWEEN EUROPE AND THE ARAB AND THE ISLAMIC WORLDS
}

\author{
Ahmed Dahroug, Mohamed Aborizka ${ }^{1}$, Martín López-Nores ${ }^{2}$ and José Juan Pazos-Arias ${ }^{2}$ \\ ${ }^{I}$ Arab Academy for Science, Technology and Maritime Transport \\ Marshal Ahmed Ismail Street square 1159, El-Sheraton buildings, Cairo, Egypt \\ ${ }^{2}$ Department of Telematics Engineering, University of Vigo \\ EE Telecomunicación, Campus Universitario s/n, Vigo, Spain
}

\begin{abstract}
Globalization and migration patterns have led to a significant intensification of the encounters between Europeans, on one hand, and Arabs and Muslims, on the other. Increasingly, politics, economics and culture transcend national boundaries, but the relations between Europe and the Arab and Islamic worlds are threatened by polarization and hostility. Grounded on theories of sociology, pedagogy and cognition, this paper presents a mobile app that seeks to promote mutual knowledge and understanding by highlighting the associations between the two sides, driven by the commonalities and disparities between the historical characters of Richard I of England and Salah ad-Din.
\end{abstract}

\section{KEYWORDS}

Mobile Applications, Historical and Cultural Symmetries, Storytelling, Multi-Perspective Education

\section{INTRODUCTION}

History and cultural heritage are often presented at schools, at museums and in the media in strongly-politicized ways that nurture attachment to the idea of homogeneous nations that transcend class divisions and erase local specificity (Phillips, 1996; Jaskulowski and Surmiak, 2017; Sung and Yang, 2009). The reinforcement of such siloed and one-sided structures of collective memory is seen as one of the most pressing contemporary challenges (Al Ashmawi et al., 2012). Accordingly, many scholars and institutions have advocated for cultural diversity and the promotion of transnational understandings of History, focusing on pedagogy to embed democratic principles of inclusion, inquiry, multiple interpretations and freedom of expression (Holden, 1996; Guyver, 2016; Bodenhamer, 2012).

Since textbooks have fixed structures, museum exhibitions are quasi-static, and most of the mass media have well-defined editorial policies (not to say ideological bias), the use of Internet-enabled devices and social networks could be one key to realizing a shift to these new models, helping people develop awareness of their own personal and national identities through an understanding of their own and others' histories and cultures (Bellino and Williams, 2017; Wong, 2015). In this line of thinking, we have developed one mobile application that delivers narratives and quiz games focused on the relationships between Europe, on the one hand, and the Arab and the Islamic worlds, on the other. The goal is to foster reflection and re-interpretation of history and heritage driven by the commonalities and disparities between two notable historical characters, namely Richard I of England and Salah ad-Din, who have been traditionally regarded as heroes by one side and villains by the other because of their roles in the Third Crusade. These two characters help to develop an interactive experience grounded on the three core principles highlighted in (Al Ashmawi et al., 2012):

1) Reflecting the diversity of Europe and the Arab and Islamic worlds.

2) Acknowledging the positive aspects of intercultural encounters.

3) Developing a multi-perspective approach to the study of the past. 
Next section presents the main features of the app, along with a set of snapshots. Section 2 summarizes the results of preliminary evaluation, conducted by means of questionnaires on a small sample of volunteers from Spain and Egypt. Section 4 contains conclusions and a motivation for further development and testing.

\section{APP DESIGN AND FEATURES}

Figure 1 shows the starting screen of the app, which provides brief descriptions and visual contents about the different locations around the Mediterranean Sea that were relevant to the lives of Richard I and Salah ad-Din, as well as to the historical event of the Third Crusade. These locations were chosen to quickly highlight the diverse cultural landscape of the 12th century and the notable differences to the political maps of the 21 st.

The app offers successive rounds of storytelling, gameplay and reflection, each one focused on a different reflective topic: "Life in year 1180//575", "Political, military and religious leaders", "Alliances around the Mediterranean", "Fighting and co-existing", "811//835 years later". These topics are weaved together by successive bits of a story (see Figure 2) that serve to confront the points of view of an English peasant and a shepherd from Jerusalem, about their societies, their political leaders, their culture, their faith, their involvement in the Battle of Jaffa, and the aftermath of the Crusade, when neither side was entirely satisfied with the results. The writing was supervised by Humanities experts in order to reinforce the increasingly-recognized capabilities of storytelling to integrate multiple viewpoints in cultural settings (Wong, 2015).


Figure 1. Initial screens 


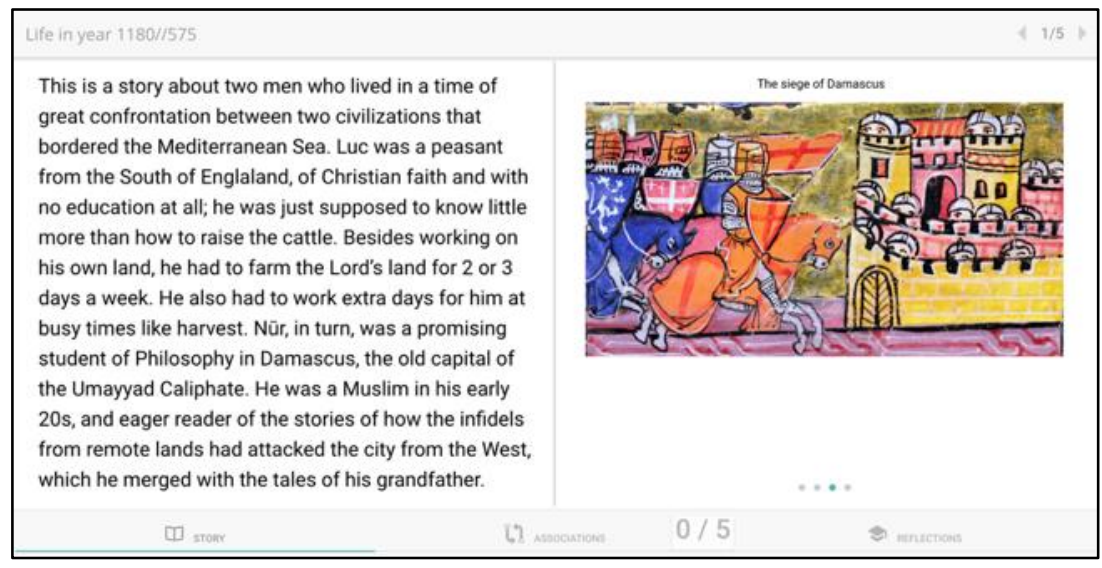

Figure 2. A bit of a story and related visual contents

The gameplay features lie within the exploration of the associations among the selected locations and the historical characters, filling in some questions left blank by the experts. Figure 3 shows a mesh of concepts and connecting properties related to the reflective topic of "Political, military and religious leaders". We have developed these associations, again with the aid of Humanities experts, in order to delve into the common and opposing features between Richard I and Salah ad-Din. Likewise, within the reflective topic of "811 or 835 years later", we have developed a symmetry between the history of Richard I of England and Salah ad-Din and the modern-day events of the Gulf Wars, trying to favor retention thanks to associations with the characters of Tony Blair (who, just like Richard I, had power in England and was educated in Oxford) and Saddam Hussein (a ruler from the Arab world, born in Tikrit, Iraq, just like Salah ad-Din).

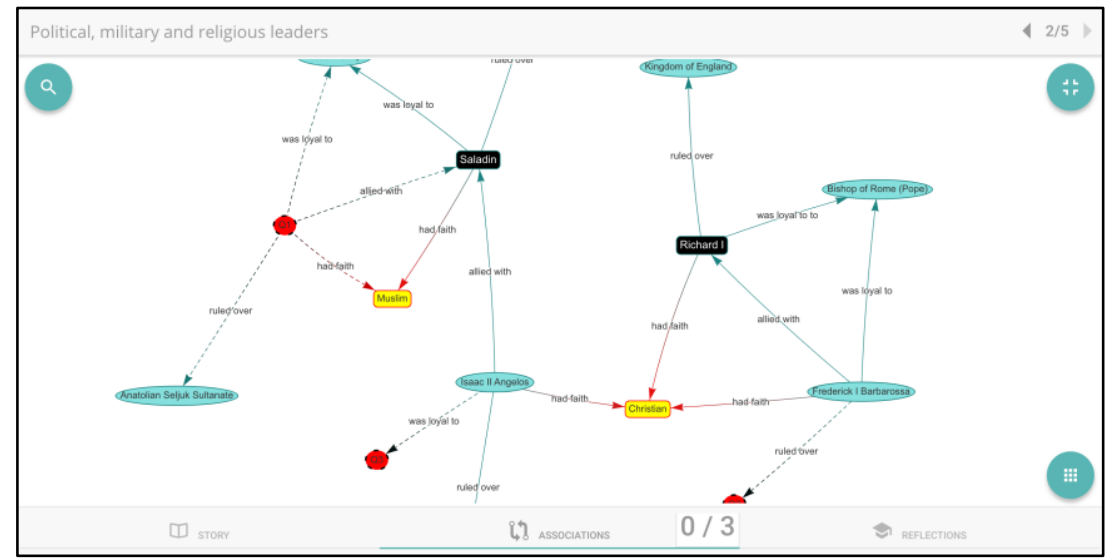

Figure 3. A mesh of associations and questions.

The user can drag the nodes around, zoom in/out and click on the pale blue nodes to display a gallery of visual contents related to the corresponding characters, locations or events. If he/she clicks on the question nodes (labeled Q1 to Q4 in Fig. 3), a pop-up appears including a question title and a set of choices (Figure 4). The user must reply correctly to all the questions before the next reflective topic is unlocked.

In relation to each reflective topic, the user can also display a handful of highlights, chosen by Humanities experts according to the messages that we aim to convey and the reflection we aim to instigate, with a particular focus on acknowledging the positive aspects of intercultural encounters before and after the 12th century. By clicking on each pieces of text, the user can again display a gallery of pictures and/or videos related to each fact. The user can give some quick feedback too, by clicking on one of the emojis of Fig. 5, to indicate different emotions: "that's good to know", "that makes me think", "that's surprising", "I knew that already" and "who cares!". This feedback is one of the sources of information for the experiments to conduct in the future for the full validation of our proposal. Prior to that, we have resorted to volunteers and questionnaires for the preliminary evaluation of the next section. 


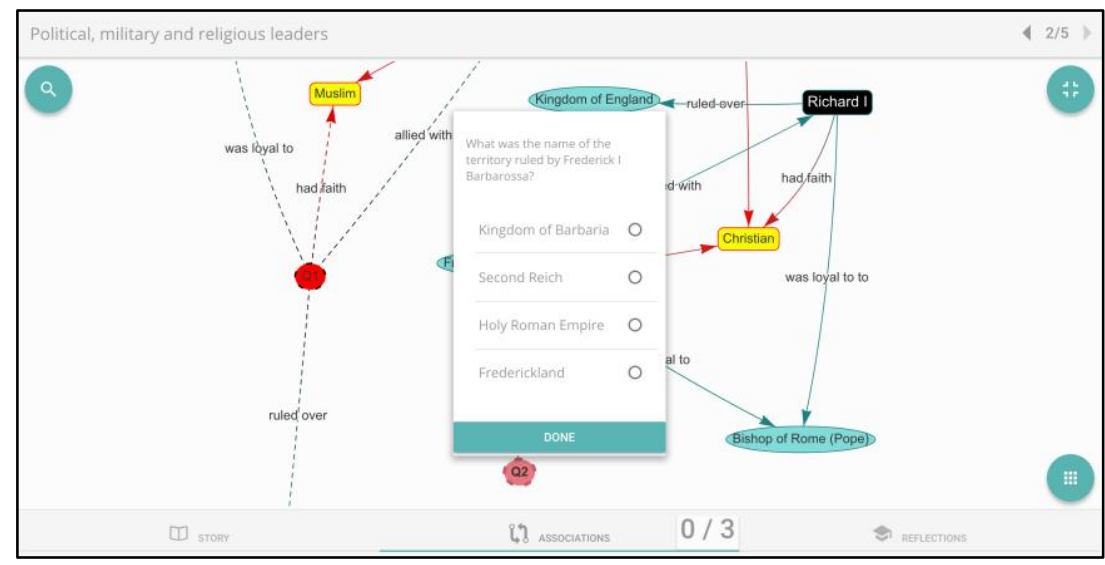

Figure 4. A multiple-choice question

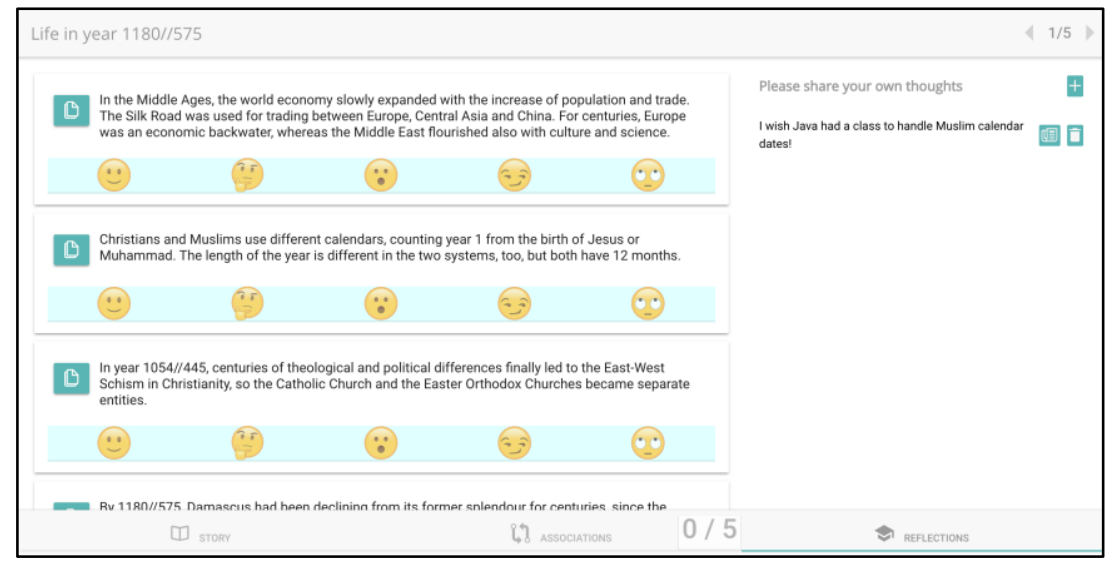

Figure 5. Seeking quick feedback about reflection points

\section{PRELIMINARY EVALUATION}

The first version of our app has been assessed in collaboration with 16 volunteers from Spain and Egypt (9+7) through experiments conducted in January and February 2019. The assessment looked at the feedback gathered through the emojis interface and the replies to a paper-based questionnaire.

The volunteers tried the app in one only session each, lasting for an average of $35 \mathrm{~min}$. Then, they proceeded to fill in the questionnaire, which contained 31 statements to rate on a Likert scale, plus 8 questions requiring textual answers (about the user experience, the features they liked the most and the least, suggested improvements, etc.). The results yield the following observations:

- While the users were faced with an average of 13.2 highlights in the app, they rated only 4.7 with one of the emojis, either because they did not read the rest of the highlights or they did not find any of the emojis to be representative enough. From among the replies, $62 \%$ of the users would express interest, thinking or surprise; $32 \%$ would click on the smirking face, and only $6 \%$ would express indifference or lack of interest.

- Nearly $1 / 4$ of the users had negative opinions about the app, and more than $1 / 3$ did not perceive much added value in the graph visualizations of concepts and associations. This datum correlates with their suggestion that it would be better to use the app on a larger screen than offered by a smartphone, and that things would be much easier to understand with a teacher or guide browsing/explaining the contents. In contrast, the features related to the bits of the stories, the multiple-choice questions and the reflection points were appealing to nearly $88 \%$ of the users. 
- $\quad 37 \%$ of the users indicated that they ended up with a richer understanding of the happenings of the 12 th century, while $56 \%$ had a neutral opinion. It is likely that the statement in the questionnaire was too ambitious for the relatively short time spent with the app.

We are using the feedback gathered during these experiments to update the implementation of the app and to complete its contents. More extensive evaluation will be conducted once the new version has been finalized, with a broader spectrum of participants and an effort to use the app in primary/secondary education settings.

\section{CONCLUSIONS AND FUTURE WORK}

We have created and tested a mobile app that aims to contribute to bridging the gap between Europe and the Arab and Islamic worlds through a new pedagogical approach, rooted on the historical and cultural similarities and differences existing among locations, characters, events and any other elements of already-established identities and dominant narratives. Our design integrates different means to instigate curiosity, reflection and re-interpretation from a multi-perspective approach.

Our preliminary evaluation has yielded positive findings that encourage us to keep improving the app, dealing with usability issues and refining the contents. Subsequent studies will focus on investigating the use of the app in educational settings, contributing to a carefully-constructed history curriculum that enables pupils to challenge stereotypes, to avoid the superficial and to develop a deep understanding of controversial histories. On the technological side, we are interested in introducing means to personalize the contents of the app according to the age and the level of historical knowledge of each student, aiming to tailor the complexity of the writing and the difficulty of the quiz game accordingly.

\section{ACKNOWLEDGEMENT}

This research received funding from the European Union's Horizon 2020 research and innovation programme under grant agreement No 693150, as well as from the European Regional Development Fund (ERDF) and the Galician Regional Government under agreement for funding the AtlantTIC Research Center for Information and Communication Technologies, and from the Ministerio de Educación y Ciencia (Gobierno de España) research project TIN2017-87604-R.

\section{REFERENCES}

Al Ashmawi, F., Reiss, W., Dougi, N., Riley, M. et al., 2021. On a common path: New approaches to writing history textbooks in Europe and the Arab and Islamic worlds: The case of the Mediterranean. http://unesdoc.unesco.org/images/0022/002270/227041e.pdf, Rabat, Morocco.

Bellino, M.J. and Williams, J.H. (Eds.), 2017. (Re)constructing memory: Education, identity, and conflict. SensePublishers, Rotterdam, The Netherlands.

Bodenhamer, D., 2012. History in the Digital Age. Routledge, London, UK.

Guyver, R. (ed.), 2016. Teaching History and the changing nation state - Transnational and intranational perspectives. Bloomsbury Academic, London, UK.

Holden, C., 1996. Enhancing History teaching through a human rights perspective. Evaluation \& Research in Education, Vol. 10, No. 2, pp. 113-127.

Jaskulowski, K. and Surmiak, A., 2017. Teaching history, teaching nationalism: A qualitative study of history teachers in a Polish post-industrial town. Critical Studies in Education, Vol. 58, No. 1, pp. 36-51.

Phillips, R., 1996. History teaching, cultural restorationism and national identity in England and Wales. Curriculum Studies, Vol. 4, No. 3, pp. 385-399, 1996.

Sung, P.-F. and Yang, M.-L., 2009. National identity and its relationship with teachers' historical knowledge and pedagogy: the case of Taiwan. Asia Pacific Journal of Education, Vol. 29, No. 2, pp. 179-194.

Wong, A., 2015. The whole story, and then some: Digital storytelling in evolving museum practice. Proceedings of Museums and the Web, Chicago (IL), USA. 